\title{
A Case Report of a 55 Year Old Female with Epulis Granulomatosa
}

\section{INTRODUCTION}

There are various soft tissue lesions that exist in the oral cavity. Epulis granulomatosum is a tumor like growth arising as a complication from a poorly healed extraction socket. ${ }^{1}$ Epulis granulomatosa is also called epulis hemangiomatosa, derived from the numerous blood vessels in the histopathological picture. The clinical presentation is that of a soft tissue tumor. It is often mistaken as other soft tissue lesions such as granulomas, fibromas etc. Proper diagnosis and treatment planning is important in such a lesion so as to avoid any delay in management of the patient.

Here, we report a case of a 55 year old female with the lesion since 2 months.

\section{CASE REPORT}

A 55 year old female patient reported to the department with a chief complaint of a growth present on the upper right back teeth region. History of present illness dated back to 2-3 days after which she noticed the growth. She underwent extraction of the maxillary right first and second molars 10 days back. The growth had not increased in size since then. The past medical history was not relevant. The extra-oral examination was non-contributory. On intra-oral examination, a reddish pink growth of size $0.5 \mathrm{~cm} \times 0.5$ $\mathrm{cm}$ (figure. 1) was noted originating from the extraction socket of 17 extending above the surface of alveolar bone, smooth-surfaced without any serosanguinous discharge. On palpation, the growth was non-tender, soft in consistency, compressible but not reducible, bleeding profusely on provocation (figure. 2). A provisional diagnosis of Epulis granulomatosum w.r.t 17 was given based on the history and clinical findings. Differential diagnoses given were giant cell granuloma, carcinoma of the maxillary antrum. Radiovisiograph (RVG) w.r.t 16, 17,
18 (figure. 3) was done which revealed empty sockets of 16,17 and an intact lamina dura was seen w.r.t 18 . Water's view (PNS) was done (figure. 4) in which no abnormality was detected in the right maxillary sinus. The patient was referred to the department of Oral Surgery for surgical excision and the histopathological examination revealed granulation tissue with numerous inflammatory cells. (figure. 5)

\section{DISCUSSION}

Epulis has been derived from Greek origin which means 'enlargement'. It can be found in the oral cavity on different sites such as gingiva, alveolar mucosa etc. It is a benign proliferation of the soft tissue present at that site. Epulis granulomatosa is a soft tissue tumor which can be termed as a proliferative reaction from an extraction socket. ${ }^{2}$ The etiology can be mostly attributed to as a sequel of a difficult extraction. Other etiologies include local irritants, poor oral hygiene etc. There is slight predilection for female gender and young age. In contrast, the patient in the present case report was middle aged. The clinical features include a smooth, lobulated or bosselated surface of a red growth on the gingiva or alveolar mucosa similar to this case. The diagnosis is based on history, clinical findings and histopathology. The differential diagnosis includes giant cell granuloma, pulse granuloma, carcinoma of maxillary antrum. ${ }^{3,4}$

Giant cell granuloma clinically appears similar to but shows the presence of giant cells which are absent in epulis granulomatosa. ${ }^{3}$

In Pulse granuloma, which appears similar on clinical and histological basis, special stain Periodic Acid Schiff (PAS) can show the presence or absence of carbohydrate. ${ }^{4}$ 
Carcinoma of maxillary sinus also presents with similar clinical findings. Given the age of the patient, it is important to rule out the possibility of the carcinoma of maxillary sinus. However, it is more common in males and radiological investigations will reveal the presence of a lesion in the maxillary sinus. Histopathologically, granulation tissue with chronic inflammatory cells is seen.

The traditional treatment includes surgical excision. Recent modalities are sclerotherapy 6 and diode laser excision. ${ }^{7}$ Recently, authors have hypothesized that the use of intralesional propranolol may prove beneficial. $^{8}$

\section{CONCLUSION}

In dental practice, various lesions are encountered. The diagnosis and treatment of Epulis granulomatosa should be done with utmost care.

\section{REFERENCES}

1. Leong R, Seng GF. Epulis granulomatosa: extraction sequelae Gen Dent. 1998;46(3):252-5.

Source of support: Nil, Conflict of interest: None declared
2. Shafer WG, Hine MK, Levy BM. A Textbook of Oral Pathology. 7th ed. Philadelphia: W.B. Saunders; 1983. p. 6o1-8.

3. Wood NK, Gauz PW. Differential diagnosis of oral and maxillofacial lesions. 5th ed. Missouri: Mosby, Elsevier; 1997. p. 142-3.

4. Manjunatha BS, Kumar GS, Raghunath V. Histochemical and polarization microscopic study of two cases of vegetable/pulse granuloma. Indian J Dent Res 2008;19:74-7.

5. Mehanna P, Smith G. Maxillary carcinoma. Can Fam Physician. 2009 Mar; 55(3): 262-4.

6. Cai Y, Sun R, He KF, Zhao YF, Zhao JH. Sclerotherapy for the recurrent granulomatous epulis with pingyangmycin. Med Oral Patol Oral Cir Bucal. 2017:1;22 (2):e214-8.

7. Sara Ghadimi, Nasim Chiniforush, Mahsa Najafi, Sepideh Amiri. Excision of Epulis Granulomatosa with Diode Laser in 8 Years Old Boy: A Case Report. J Lasers Med Sci 2015;6(2):92-5.

8. Liu C, Qin ZP, Fan ZN, Zhao WJ, Wang YM, Wei FC, Li KL, Liu SH. New treatment strategy for granulomatous epulis: intralesional injection of propranolol Med Hypotheses. $2012 ; 78(2): 327-9$.

\section{Corresponding Author:}

Dr. K. Aravinda

Professor and Head

Department of Oral Medicine and Radiology

Swami Devi Dyal Hospital and Dental College

Barwala, Panchkula, India
For article enquiry/author contact details, e-mail at: manuscriptenquiry.ihrj@gmail.com 


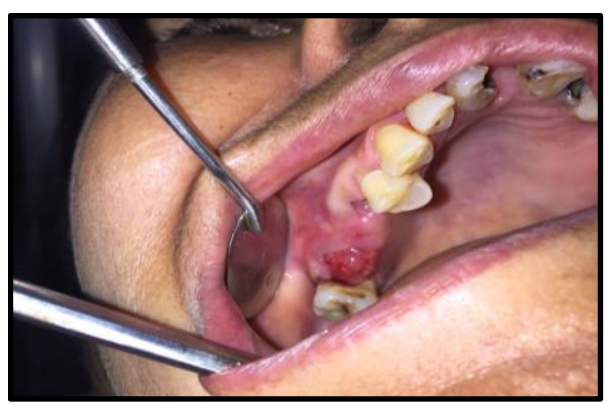

Figure 1. Reddish pink growth seen w.r.t extraction socket

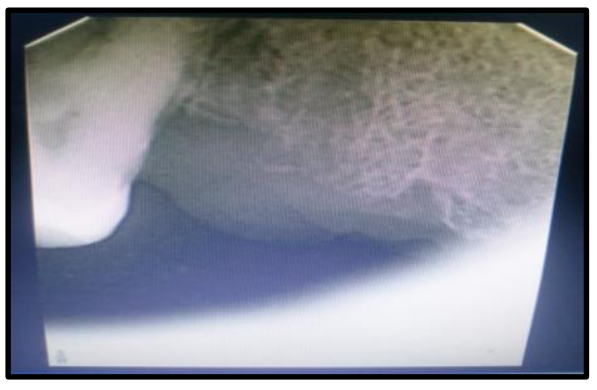

Figure 3. RVG wrt 16, 17 show empty sockets. 18 is seen with intact lamina dura

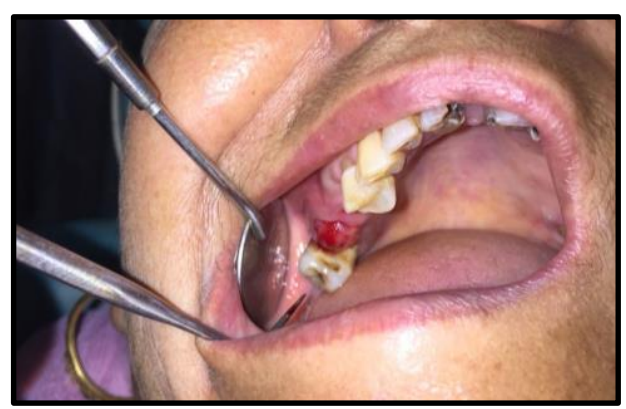

Figure 2. Bleeding on probing present

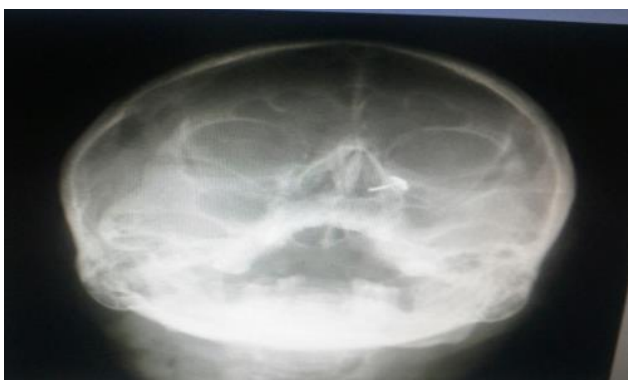

Figure 4. PNS view seen in which no pathology is detected 